\title{
Relationship Between Body Composition and the Histology of Non-alcoholic Fatty Liver Disease: A Cross-sectional Study
}

\section{Teruki Miyake}

Ehime University Graduate School of Medicine

Masumi Miyazaki

Ehime University Graduate School of Medicine

Osamu Yoshida

Ehime University Graduate School of Medicine

\section{Sayaka Kanzaki}

Ehime University Graduate School of Medicine

Hironobu Nakaguchi

Ehime University Graduate School of Medicine

Yoshiko Nakamura

Ehime University Graduate School of Medicine

Takao Watanabe

Ehime University Graduate School of Medicine

Yasunori Yamamoto

Ehime University Graduate School of Medicine

Yohei Koizumi

Ehime University Graduate School of Medicine

Yoshio Tokumoto

Ehime University Graduate School of Medicine

Masashi Hirooka

Ehime University Graduate School of Medicine

Shinya Furukawa

Ehime University

\section{Eiji Takeshita}

Ehime University Graduate School of Medicine

\section{Teru Kumagi}

Ehime University Graduate School of Medicine

Yoshio Ikeda

Ehime University Graduate School of Medicine

Masanori Abe 
Ehime University Graduate School of Medicine

\section{Kumiko Toshimitsu}

Ehime University Hospital

\section{Bunzo Matsuura}

Ehime University Graduate School of Medicine

Yoichi Hiasa ( $\nabla$ hiasa@m.ehime-u.ac.jp)

Ehime University Graduate School of Medicine

\section{Research Article}

Keywords: fat mass, muscle mass, non-alcoholic steatohepatitis, liver fibrosis, visceral fat

Posted Date: February 1st, 2021

DOl: https://doi.org/10.21203/rs.3.rs-144447/v1

License: (c) (i) This work is licensed under a Creative Commons Attribution 4.0 International License. Read Full License

Version of Record: A version of this preprint was published at BMC Gastroenterology on April 13th, 2021. See the published version at https://doi.org/10.1186/s12876-021-01748-y. 


\section{Abstract}

Background: Causes of non-alcoholic fatty liver disease and its progression include visceral fat accumulation and loss of muscle mass; however, which is more critical is unclear. To clarify this, we examined the relationship between body composition and non-alcoholic fatty liver disease progression as indicated by fibrosis and the non-alcoholic fatty liver disease activity score.

Methods: This cross-sectional study comprised 139 patients (54 men; age, 20-76 years) treated for nonalcoholic fatty liver disease between December 2010 and January 2020. Body composition measurements, histological examinations of liver samples, and comprehensive blood chemistry tests were performed. The relationship between body composition and non-alcoholic fatty liver disease histology findings was analyzed using the logistic regression model.

Results: Fibrosis was significantly and inversely correlated with muscle mass and appendicular skeletal muscle mass and significantly and positively correlated with fat mass, fat mass/height squared, visceral fat area, and waist-hip ratio $(P<0.05)$. After adjustment for sex, blood chemistry measurements, and body composition indices, fibrosis remained associated with appendicular skeletal muscle mass, fat mass, fat mass/height squared, and visceral fat area $(P<0.05)$. Non-alcoholic fatty liver disease activity score $\geq 5$ significantly correlated with fat mass and fat mass/height squared in a univariate but not multivariate analysis.

Conclusions: Fibrosis in non-alcoholic fatty liver disease, an indicator of unfavorable long-term outcomes, is associated with more indices of fat mass than of those of muscle mass. Hence, fat mass should be controlled to prevent non-alcoholic fatty liver disease progression.

\section{Background}

Non-alcoholic fatty liver disease (NAFLD) is one of the most common hepatic diseases and a manifestation of metabolic syndrome [1,2]. NAFLD is a risk factor for various metabolic and cardiovascular diseases, and it can also progress to cirrhosis and liver failure [2-4]. Therefore, clinicians need to understand the pathophysiology of NAFLD and closely monitor NAFLD-patients to prevent serious complications and NAFLD progression.

The causes of NAFLD are various. Several studies associate NAFLD with fat accumulation and loss of muscle mass [5-9]. Lack of exercise and overeating increase the size of the fat mass, particularly the amount of visceral adipose tissue (VAT). VAT accumulation induces insulin resistance and exacerbates liver damage in NAFLD [5]. Loss of skeletal muscle mass (i.e., sarcopenia) is associated with diabetes, metabolic syndrome, and cardiovascular disease and is a risk factor for non-alcoholic steatohepatitis (NASH) and fibrosis ( $\geq F 2$ ) [6-10]. However, to our knowledge, no studies have compared the contributions of fat mass and muscle mass to NAFLD histology, and it is unclear whether one of these factors is more critical than the other. 
Elucidating the relationship between body composition and NAFLD is important for identifying patients at high risk of NAFLD progression. We examined this relationship using fibrosis stage and the NAFLD activity score (NAS) as indicators of NAFLD progression. We also determined whether muscle mass or fat mass was more involved in NAFLD pathology.

\section{Methods}

\section{Participants}

We enrolled 145 patients with NAFLD (55 men and 90 women) aged 20-76 years who were treated from December 2010 to January 2020 at a single hospital. Patients were eligible for the study if they were diagnosed with fatty liver via liver biopsy and had either elevated liver enzyme levels or imaging (ultrasonography or computed tomography) findings indicative of possible liver injury, their body composition was evaluated within 3 days before and after the liver biopsy, they had no liver diseases of other etiologies, they consumed $<30 \mathrm{~g} /$ day (men) or $<20 \mathrm{~g} /$ day (women) of alcohol, and they had no evidence of decompensated liver failure or hepatocellular carcinoma. Patient datasets were numerically coded to preserve anonymity, and data were housed in a secure database. Six patients were excluded because their data were missing $(n=2)$ or because they used steroids $(n=2)$, had cancer $(n=1)$, and/or were otherwise deemed inappropriate for this study $(n=1)$. Finally, 139 patients (54 men and 85 women) were included in the study, and their medical records were analyzed.

This cross-sectional study was conducted in accordance with the ethical guidelines of the 1975 Declaration of Helsinki as revised in 1983 and was approved by the Ethics Committee of Ehime University Hospital (approval ID number: 1012004, 1709008; University Hospital Medical Information Network ID: UMIN000010659, UMIN 000030222). All study participants provided informed consent.

\section{Patient evaluation}

Results of physical and biochemical examinations were assessed. Fasting venous blood samples were taken on the morning of the second day of hospitalization. Body composition, including skeletal muscle mass and body fat mass, was determined using an InBody720 analyzer (Biospace Corporation Limited, Seoul, Korea), with the patients wearing light gowns but not shoes. For biochemical analysis, the levels of alanine aminotransferase (ALT), y-glutamyl transpeptidase (GGT), creatinine (Cre), hemoglobin A1c $(\mathrm{HbA} 1 \mathrm{c})$, total cholesterol (TC), and triglycerides (TGs) were measured.

\section{Histological assessment}

All patients in this study underwent percutaneous liver biopsy assisted by ultrasonography or laparoscopy. The liver specimens were embedded in paraffin and stained with hematoxylin \& eosin and reticulin silver. Two experienced hepatopathologists who were blinded to the clinical features examined the liver biopsy specimens. 
The NAS, which is the sum of the scores for steatosis (grade $0-3$ ), lobular inflammation (grade 0-3), and ballooning degeneration (grade 0-2) [11], was recorded for each patient. Patients with an NAS $\geq 5$ were diagnosed with NASH. Hepatic fibrosis was staged as described in previous reports: stage 0 , absence of fibrosis; stage 1a, delicate perisinusoidal fibrosis; stage 1b, dense perisinusoidal fibrosis; stage 1c, portalonly fibrosis without perisinusoidal fibrosis; stage 2, combined perisinusoidal and portal/periportal fibrosis; stage 3, bridging fibrosis; and stage 4, cirrhosis [12].

\section{Statistical analysis}

The Wilcoxon test, Kruskal-Wallis test, unpaired t-test, one-way analysis of variance, and logistic regression analysis were performed using JMP software (version 14.2; SAS Institute, Cary, NC, USA). Odds ratios (ORs) and their 95\% confidence intervals (Cls) were determined to assess the relationship between the histological features of NAFLD and the indices of body composition. Factors that were significant in a univariate analysis were included in a multivariate analysis that was adjusted for the following potential confounding factors: age; sex; ALT, Cre, HbA1c, TC, and TG levels; and body composition indices, namely, muscle mass, muscle mass divided by height squared $\left(\mathrm{ht}^{2}\right)$, fat mass, or fat mass divided by ht ${ }^{2}$. Data are expressed as median (interquartile range) or number (percentage). A Pvalue of $<0.05$ was considered statistically significant.

\section{Results}

\section{Patient characteristics}

Table 1 shows the patients' characteristics. The median muscle mass, median muscle mass/ht2, appendicular skeletal muscle mass (ASM), ASM/ht2, fat mass, fat mass $/ \mathrm{ht} 2$, and visceral fat area were $23.5 \mathrm{~kg}$ (range $20.1-30.0 \mathrm{~kg}$ ), $9.6 \mathrm{~kg} / \mathrm{m} 2$ (range, $8.6-10.7 \mathrm{~kg} / \mathrm{m} 2$ ), $17.7 \mathrm{~kg}$ (range, 22.3-14.6 kg), 7.2 $\mathrm{kg} / \mathrm{m} 2$ (range, $6.2-8.1 \mathrm{~kg} / \mathrm{m} 2$ ), $24.7 \mathrm{~kg}$ (range, $18.8-31.9 \mathrm{~kg}$ ), $10 \mathrm{~kg} / \mathrm{m} 2$ (range, $7.5-12.5 \mathrm{~kg} / \mathrm{m} 2$ ), and $129.4 \mathrm{~cm} 2$ (range, $110.9-156.4 \mathrm{~cm} 2$ ), respectively.

\section{Table 1. Patient characteristics}




\begin{tabular}{|ll|}
\hline Variable & Median (IQR) \\
\hline Age, years & $59(46-67)$ \\
\hline Sex, $\mathrm{n}(\mathrm{male} / \mathrm{female})$ & $54 / 85$ \\
\hline Body mass index, $\mathrm{kg} / \mathrm{m}^{2}$ & $28.0(24.8-31.1)$ \\
\hline Alanine aminotransferase, $\mathrm{U} / \mathrm{L}$ & $65(37--102)$ \\
\hline Y-Glutamyl transpeptidase, $\mathrm{U} / \mathrm{L}$ & $60(35-111)$ \\
\hline Creatinine, $\mu$ mol/L & $60.1(49.5-75.1)$ \\
\hline Hemoglobin A1c, \% & $6.3(5.7-7.3)$ \\
\hline Total cholesterol, mmol/L & $4.9(4.2-5.6)$ \\
\hline Triglycerides, mmol/L & $1.5(1.1-2.0)$ \\
\hline Muscle mass, $\mathrm{kg}$ & $23.5(20.1-30)$ \\
\hline Muscle mass/ht ${ }^{2}, \mathrm{~kg} / \mathrm{m}^{2}$ & $9.6(8.6-10.7)$ \\
\hline ASM, $\mathrm{kg}$ & $17.7(22.3-14.6)$ \\
\hline ASM/ht ${ }^{2}, \mathrm{~kg} / \mathrm{m}^{2}$ & $7.2(6.2-8.1)$ \\
\hline Muscle mass (upper extremity), $\mathrm{kg}$ & $4.8(3.9-6.2)$ \\
\hline Muscle mass (upper extremity)/ht ${ }^{2} \mathrm{~kg} / \mathrm{m}^{2}$ & $2(1.7-2.2)$ \\
\hline Muscle mass of lower extremity, $\mathrm{kg}$ & $13.2(10.7-16.0)$ \\
\hline Muscle mass of lower extremity/ht ${ }^{2} \mathrm{~kg} / \mathrm{m}^{2}$ & $5.2(4.6-5.8)$ \\
\hline Fat mass, $\mathrm{kg}$ & $24.7(18.8-31.9)$ \\
\hline Fat mass/ht ${ }^{2}, \mathrm{~kg} / \mathrm{m}^{2}$ & $10(7.5-12.5)$ \\
\hline Visceral fat area, cm ${ }^{2}$ & $129.4(110.9-156.4)$ \\
\hline Waist-hip ratio & $0.96(0.91-1.00)$ \\
\hline
\end{tabular}

IQR, interquartile range; $\mathrm{ht}^{2}$, height squared; ASM, appendicular skeletal muscle mass

\section{Relationship between histological findings and body composition}

Fat mass/ht2, visceral fat area, and the waist-hip ratio were significantly higher in patients with highstage fibrosis than in patients without fibrosis (Table 2). However, fat mass did not differ significantly according to the fibrosis stage, nor did any of the muscle mass indices. Muscle mass/ht2, ASM/ht2, 
muscle mass of upper extremity/ht2, muscle mass of lower extremity/ht2, fat mass, and visceral fat area were significantly higher in patients with severe steatosis than in patients with mild steatosis (Additional file 1). There were no significant differences in the lobular inflammation grade or ballooning grade between these groups (Additional files 2 and 3). Fat mass and fat mass/ht2 were significantly higher in patients with a high versus low NAS, whereas muscle mass, visceral fat area, and the waist-hip ratio were unrelated to the NAS (Table 3).

\section{Table 2. Body composition according to the stage of fibrosis}

\begin{tabular}{|c|c|c|c|c|}
\hline \multirow[t]{2}{*}{ Index } & \multicolumn{3}{|l|}{ Median (IQR) } & \multirow{2}{*}{$\begin{array}{l}\mathrm{P} \text { - } \\
\text { value }\end{array}$} \\
\hline & $\begin{array}{l}\text { Stage } 0(n= \\
27)\end{array}$ & $\begin{array}{l}\text { Stage } 1-2(n= \\
57)\end{array}$ & $\begin{array}{l}\text { Stage } 3-4(n= \\
55)\end{array}$ & \\
\hline Muscle mass, kg & $\begin{array}{l}27.4(22.4- \\
32.4)\end{array}$ & $\begin{array}{l}22.8(19.8- \\
30.1)\end{array}$ & $\begin{array}{l}23.4(19.6- \\
28.9)\end{array}$ & 0.07 \\
\hline Muscle mass $/ \mathrm{ht}^{2}, \mathrm{~kg} / \mathrm{m}^{2}$ & $9.8(9.3-11.0)$ & $9.4(8.3-10.7)$ & $9.6(8.4-10.6)$ & 0.18 \\
\hline ASM, kg & $\begin{array}{l}20.9(16.1- \\
23.8)\end{array}$ & $\begin{array}{l}16.5(14.4- \\
21.9)\end{array}$ & $\begin{array}{l}17.5(14.1- \\
21.8)\end{array}$ & 0.09 \\
\hline $\mathrm{ASM} / \mathrm{ht}^{2}, \mathrm{~kg} / \mathrm{m}^{2}$ & $7.4(7.0-8.2)$ & $7(6.1-7.9)$ & $7.1(6.2-8.2)$ & 0.27 \\
\hline $\begin{array}{l}\text { Muscle mass of upper extremity, } \\
\mathrm{kg}\end{array}$ & $5.4(4.3-6.4)$ & $4.7(3.8-6.1)$ & $4.6(3.8-6.2)$ & 0.19 \\
\hline $\begin{array}{l}\text { Muscle mass of upper } \\
\text { extremity } / \mathrm{ht}^{2}, \mathrm{~kg} / \mathrm{m}^{2}\end{array}$ & $2(1.8-2.3)$ & $2(1.6-2.2)$ & $2(1.6-2.3)$ & 0.65 \\
\hline $\begin{array}{l}\text { Muscle mass of lower extremity, } \\
\mathrm{kg}\end{array}$ & $\begin{array}{l}15.4(12.2- \\
17.6)\end{array}$ & $\begin{array}{l}12.1(10.4- \\
15.8)\end{array}$ & $\begin{array}{l}12.5(10.3- \\
15.5)\end{array}$ & 0.06 \\
\hline $\begin{array}{l}\text { Muscle mass of lower } \\
\text { extremity } / \mathrm{ht}^{2}, \mathrm{~kg} / \mathrm{m}^{2}\end{array}$ & $5.6(5.1-5.9)$ & $5.1(4.5-5.7)$ & $5.1(4.5-6.0)$ & 0.13 \\
\hline Fat mass, kg & $\begin{array}{l}22.3(12.3- \\
26.0)\end{array}$ & $\begin{array}{l}25.9(20.3- \\
31.7)\end{array}$ & $\begin{array}{l}26.5(18.9- \\
34.0)\end{array}$ & 0.06 \\
\hline Fat mass $/ \mathrm{ht}^{2}, \mathrm{~kg} / \mathrm{m}^{2}$ & $8.6(4.6-11.0)$ & $10.1(7.8-12.7)$ & $10.3(7.6-14.2)$ & 0.04 \\
\hline Visceral fat area, $\mathrm{cm}^{2}$ & $\begin{array}{l}113.1(85.6- \\
138.8)\end{array}$ & $\begin{array}{l}129.4(113.7- \\
153.5)\end{array}$ & $\begin{array}{l}138.4(116.8- \\
163.5)\end{array}$ & 0.02 \\
\hline Waist-hip ratio & $\begin{array}{l}0.92(0.89- \\
0.96)\end{array}$ & $\begin{array}{l}0.96(0.92- \\
0.99)\end{array}$ & $\begin{array}{l}0.98(0.92- \\
1.01)\end{array}$ & $<0.01$ \\
\hline
\end{tabular}

IQR, interquartile range; $\mathrm{ht}^{2}$, height squared; ASM, appendicular skeletal muscle mass 
Table 3. Body composition according to the non-alcoholic fatty liver disease activity score (NAS)

\begin{tabular}{|llll|}
\hline Index & Median (IQR) & & P-value \\
\cline { 2 - 3 } & NAS 0-4 $(\mathrm{n}=64)$ & NAS 5-8 $(\mathrm{n}=75)$ & \\
\hline Muscle mass, $\mathrm{kg}$ & $24.3(20.3-29.9)$ & $23.2(20.1-30.0)$ & 0.94 \\
\hline Muscle mass $/ \mathrm{ht}^{2}, \mathrm{~kg} / \mathrm{m}^{2}$ & $9.6(8.6-10.5)$ & $9.6(8.5-11.1)$ & 0.5 \\
\hline ASM, $\mathrm{kg}$ & $18.4(14.2-22.3)$ & $17.6(14.7-22.3)$ & 0.87 \\
\hline ASM $/ \mathrm{ht}^{2}, \mathrm{~kg} / \mathrm{m}^{2}$ & $7.2(6.1-7.9)$ & $7.2(6.3-8.3)$ & 0.49 \\
\hline Muscle mass of upper extremity, $\mathrm{kg}$ & $4.8(3.8-6.2)$ & $4.7(3.9-6.3)$ & 0.85 \\
\hline Muscle mass of upper extremity $/ \mathrm{ht}^{2}, \mathrm{~kg} / \mathrm{m}^{2}$ & $1.9(1.7-2.2)$ & $2(1.7-2.3)$ & 0.29 \\
\hline Muscle mass of lower extremity, $\mathrm{kg}$ & $13.5(10.3-16)$ & $13(10.9-16)$ & 0.92 \\
\hline Muscle mass of lower extremity $/ \mathrm{ht}^{2}, \mathrm{~kg} / \mathrm{m}^{2}$ & $5.2(4.5-5.8)$ & $5.2(4.6-6)$ & 0.58 \\
\hline Fat mass, $\mathrm{kg}$ & $22.9(15.3-28.7)$ & $26.9(20.9-34.5)$ & $<0.01$ \\
\hline Fat mass $/ \mathrm{ht}^{2}, \mathrm{~kg} / \mathrm{m}^{2}$ & $9.1(6.1-11.5)$ & $10.6(8.4-13.4)$ & $<0.01$ \\
\hline Visceral fat area, $\mathrm{cm}^{2}$ & $126.7(104.1-153.0)$ & $132.8(115.7-157.0)$ & 0.11 \\
\hline Waist-hip ratio & $0.95(0.91-0.99)$ & $0.96(0.92-1.00)$ & 0.17 \\
\hline
\end{tabular}

IQR, interquartile range; $\mathrm{ht}^{2}$, height squared; ASM, appendicular skeletal muscle mass

Fat mass indices are more strongly associated with fibrosis than are muscle mass indices

In the univariate analysis, fibrosis ( $\geq$ Stage 1 ) significantly correlated with muscle mass (OR: $0.93,95 \% \mathrm{Cl}$ : 0.87-0.99), ASM (OR: 0.92, 95\% Cl: 0.85-0.99), fat mass (OR: 1.07, 95\% Cl: 1.02-1.13), fat mass/ht2 (OR: $1.22,95 \% \mathrm{Cl}: 1.08-1.41$ ), visceral fat area (OR: 1.02, 95\% Cl: $1.01-1.04)$, and the waist-hip ratio (OR: $1.78 \times 10595 \% \mathrm{Cl}: 76.8-1.06 \times 109)$ (Table 4). The factors that remained significant in a multivariate analysis adjusted for sex; age; body composition; and ALT, Cre, HbA1c, TC, and TG levels were as follows: ASM (adjusted OR: 0.84, 95\% Cl: 0.71-0.99), fat mass (adjusted OR: 1.09, 95\% Cl: 1.01-1.18), fat mass/ht2 (adjusted OR: 1.28, 95\% Cl: 1.04-1.62), and visceral fat area (adjusted OR: 1.02, 95\% Cl: 1.001.04) (Table 4).

Having an NAS $\geq 5$, which is indicative of NASH, was significantly associated with fat mass (OR: 1.07, 95\% Cl: 1.02-1.13) and fat mass/ht2 (OR: 1.22, 95\% Cl: 1.08-1.41) in the univariate analysis, but was not associated with either of these parameters in the multivariate analysis (Table 5). 
Table 4. Association of body composition with fibrosis ( $\geq$ Stage 1 )

\begin{tabular}{|c|c|c|c|c|}
\hline \multirow[t]{2}{*}{ Index } & \multicolumn{2}{|l|}{ Univariate analysis } & \multicolumn{2}{|l|}{ Multivariate analysis } \\
\hline & OR $(95 \% \mathrm{Cl})$ & $\begin{array}{l}\mathrm{P}- \\
\text { value }\end{array}$ & OR $(95 \% \mathrm{Cl})$ & $\begin{array}{l}\mathrm{P}- \\
\text { value }\end{array}$ \\
\hline Muscle mass, kg & $0.93(0.87-0.99)$ & 0.03 & $0.84(0.87-1)$ & $0.056^{a}$ \\
\hline $\begin{array}{l}\text { Muscle mass } / \mathrm{ht}^{2} \\
\mathrm{~kg} / \mathrm{m}^{2}\end{array}$ & $0.79(0.60-1.04)$ & 0.09 & & \\
\hline ASM, kg & $0.92(0.85-0.99)$ & 0.03 & $0.84(0.71-0.99)$ & $0.04^{\mathrm{a}}$ \\
\hline ASM $/ \mathrm{ht}^{2}, \mathrm{~kg} / \mathrm{m}^{2}$ & $0.77(0.56-1.04)$ & 0.09 & & \\
\hline Fat mass, $\mathrm{kg}$ & $1.07(1.02-1.13)$ & 0.01 & $1.09(1.01-1.18)$ & $0.03^{b}$ \\
\hline Fat mass $/ \mathrm{ht}^{2}, \mathrm{~kg} / \mathrm{m}^{2}$ & $1.22(1.08-1.41)$ & $<0.01$ & $1.28(1.04-1.62)$ & $0.03^{c}$ \\
\hline Visceral fat area, $\mathrm{cm}^{2}$ & $1.02(1.01-1.04)$ & $<0.01$ & $1.02(1.0002-1.04)$ & $0.048^{b}$ \\
\hline Waist-hip ratio & $\begin{array}{l}1.78 \times 10^{5}(76.8-1.06 \times \\
\left.10^{9}\right)\end{array}$ & $<0.01$ & $\begin{array}{l}1.44 \times 10^{4}(0.31-2.23 \times \\
\left.10^{9}\right)\end{array}$ & $0.09^{c}$ \\
\hline
\end{tabular}

Age and sex and alanine aminotransferase, creatinine, hemoglobin A1c, total cholesterol, and triglyceride levels were used as covariates, along with ${ }^{\mathrm{a}}$ at mass, ${ }^{\mathrm{b}}$ muscle mass, and ${ }^{\mathrm{C}}$ muscle mass $/ \mathrm{ht}^{2}$.

$\mathrm{OR}$, odds ratio; $\mathrm{Cl}$, confidence interval; $\mathrm{ht}^{2}$, height squared; $\mathrm{ASM}$, appendicular skeletal muscle mass

Table 5. Association between body composition and a non-alcoholic fatty liver disease activity score $\geq 5$ 


\begin{tabular}{|lllll|}
\hline Index & Univariate analysis & \multicolumn{2}{l|}{ Multivariate analysis } \\
\cline { 2 - 5 } & OR $(95 \% \mathrm{Cl})$ & P-value & OR $(95 \% \mathrm{Cl})$ & P-value \\
\hline Muscle mass, $\mathrm{kg}$ & $1.01(0.95-1.06)$ & 0.84 & & \\
\hline Muscle mass $/ \mathrm{ht}^{2}, \mathrm{~kg} / \mathrm{m}^{2}$ & $1.10(0.89-1.39)$ & 0.38 & & \\
\hline ASM, $\mathrm{kg}$ & $1.01(0.95-1.08)$ & 0.7 & & \\
\hline ASM $/ \mathrm{ht}^{2}, \mathrm{~kg} / \mathrm{m}^{2}$ & $1.15(0.89-1.49)$ & 0.29 & & $0.91^{\mathrm{a}}$ \\
\hline Fat mass, $\mathrm{kg}$ & $1.06(1.02-1.11)$ & $<0.01$ & $1.004(0.94-1.07)$ & $0.96^{\mathrm{b}}$ \\
\hline Fat mass $/ \mathrm{ht}^{2}, \mathrm{~kg} / \mathrm{m}^{2}$ & $1.17(1.07-1.3)$ & $<0.01$ & $1.11(0.02-50.5)$ & \\
\hline Visceral fat area, $\mathrm{cm}^{2}$ & $1.01(1.00-1.02)$ & 0.11 & & \\
\hline Waist-hip ratio & $62.8\left(0.32-1.69 \times 10^{4}\right)$ & 0.13 & & \\
\hline
\end{tabular}

Age and sex and alanine aminotransferase, creatinine, hemoglobin A1c, total cholesterol, and triglyceride levels were used as covariates along with ${ }^{\mathrm{a}}$ muscle mass and ${ }^{\mathrm{b}}$ muscle mass $/ \mathrm{ht}^{2}$.

$\mathrm{OR}$, odds ratio; $\mathrm{Cl}$, confidence interval; $\mathrm{ht}^{2}$, height squared; $\mathrm{ASM}$, appendicular skeletal muscle mass

\section{Discussion}

In this cross-sectional cohort study, we examined the relationship between the histological progression of NAFLD and body composition. We found that fibrosis in NAFLD was associated with more fat mass indices than muscle mass indices. Furthermore, our results remained significant after adjusting for possible confounders. Our findings suggest that the pathophysiology of NAFLD may be more dependent on fat accumulation than on loss of muscle mass. Hence, fat mass should be monitored to prevent the progression of NAFLD and to avoid serious complications such as liver failure and hepatocellular carcinoma.

The effect of visceral fat deposition on the pathology of NAFLD has been reported previously [13]. Overnutrition increases the size of the fat mass, and the accumulated fat, particularly the VAT, supplies fatty acids to the liver. When in excess, fatty acids exacerbate steatosis [14-16], worsen lipid metabolism, generate reactive oxygen species, and injure the liver [17-19]. Additionally, disturbed adipocytokines in the accumulated VAT promote hepatic steatosis [20-22] and the production of proinflammatory macrophages $[23,24]$ and are associated with the development of NASH. Subcutaneous adipose tissue (SAT) also affects the pathogenesis of NAFLD. The number of macrophages in the SAT correlates with the amount of liver fat [25], and macrophage infiltration is significantly elevated in the deep, but not in the superficial, SAT in obese patients with NASH [26]. The expression of gene products that regulate inflammation in the SAT also correlates with the amount of liver fat, as well as with the histological features of NAFLD. Gene 
expression patterns in both the VAT and SAT suggest that these tissues promote the pathological progression of NAFLD through similar mechanisms [27].

In our study, muscle mass was unrelated to the histological severity of NAFLD. In a previous study of 123 patients with biopsy-confirmed NASH and 117 patients with biopsy-confirmed non-alcoholic fatty liver, sarcopenia (defined as an ASM/body weight value two standard deviations below the average for healthy young adults) significantly correlated with significant fibrosis ( $\mathrm{ZF} 2)$ and NASH after adjusting for obesity, metabolic factors, and insulin resistance [8]. Moreover, in a report of 225 patients with NAFLD diagnosed via liver biopsy, sarcopenia (defined as an ASM/body weight value $\leq 37$ in men and $\leq 28$ in women) significantly correlated with the severity of fibrosis and steatosis after adjustment for metabolic risk factors [9]. In contrast, a review of 136 patients with NASH and 129 patients with alcoholic liver disease found no association between sarcopenia (defined as an L3 skeletal muscle area/height/height value $<50$ in men and $<39$ in women) and poor wait-list outcomes, such as increased delisting risk and poorer wait-list survival [28]. Our study, unlike the aforementioned studies, did not include a cutoff value. Further investigation is required to clarify the association between muscle mass and NAFLD. However, a study by Alferink et al. provided partial support for our results [29]. The investigators examined data from the 4609 participants of the Rotterdam study, a population-based study in the Netherlands that evaluated body composition using dual-energy $\mathrm{X}$-ray absorptiometry scanning, hepatic steatosis using abdominal ultrasonography, liver stiffness using transient elastography, grip strength using a hydraulic hand dynamometer, and gait speed using the GAITRite walkway [29]. The participants were stratified by sex and $\mathrm{BMI}$, and the results demonstrated that high fat mass and fat distribution were more strongly associated with the high prevalence of NAFLD than was low muscle mass, while the high prevalence of presarcopenia and sarcopenia was not associated with high prevalence of NAFLD. Additionally, in normal-weight women, higher muscle mass was associated with a lower prevalence of both NAFLD and liver stiffness. Histological findings were not examined [29].

The strengths of our study are that patients were diagnosed with NAFLD via liver biopsy and that the examination of whole-body fat mass and muscle mass was conducted at the same facility under the same conditions. However, our study also had several limitations. First, our study participants were all Japanese. Body composition differs among races; therefore, whether our results can be generalized to other races is uncertain. Second, we did not measure skeletal muscle strength and function [30] and did not examine the relationship between NAFLD histology and sarcopenia. However, our aim for this study was to examine the relationship between body composition and NAFLD histology. Finally, because our study design was cross-sectional, a causal relationship between NAFLD and body composition could not be established. Therefore, whether patients with an enlarged fat mass are at high risk for NAFLD progression remains unknown. Future prospective validation studies are necessary to address these limitations.

\section{Conclusions}


Despite its limitations, our study had several notable results. Particularly, it associates fibrosis, an indicator of unfavorable long-term outcomes, with indices of fat accumulation in patients with NAFLD and suggests that fat mass more strongly impacts the pathophysiology of NASH than muscle mass does. Therefore, correct recognition is critical for identifying patients at high risk of NAFLD progression.

\section{List Of Abbreviations}

ALT, alanine aminotransferase; CRE, creatinine; GGT, $\gamma$-glutamyl transpeptidase; HbA1c, hemoglobin A1c; NAFLD, Non-alcoholic fatty liver disease; TC, total cholesterol; TG, triglycerides; VAT, visceral adipose tissue.

\section{Declarations}

\section{Ethics approval and consent to participate}

This cross-sectional study was conducted in accordance with the ethical guidelines of the 1975 Declaration of Helsinki as revised in 1983 and was approved by the Ethics Committee of Ehime University Hospital (approval ID number: 1012004, 1709008; University Hospital Medical Information Network ID: UMIN000010659, UMIN 000030222). All study participants provided informed consent.

\section{Consent for publication}

\section{Availability of data and materials}

The datasets used and/or analysed during the current study are available from the corresponding author on reasonable request.

\section{Competing interests}

All authors declare that they have no conflict of interest.

\section{Funding}

This work was supported by JSPS KAKENHI [Grant Number JP19K11743] and a research grant from Ehime University.

\section{Author contributions}

Conceptualization, T.M., O.Y., and Y.H.; methodology, T.M., M.M., and O.Y.; software, T.M. and S.F.; validation, T.M., M.M., B.M., and Y.H.; formal analysis, T.M., M.H., and S.F.; investigation, T.M., M.M, O.Y., S.K., H.N., Y.N., T.W., Y.Y., Y.K., Y.T., M.H., S.F., E.T., T.K., Y.I., M.A., K.T., B.M., and Y.H.; resources, X.X.; data curation, T.M., M.M, O.Y., S.K., H.N., Y.N., T.W., Y.Y., Y.K.; writing-original draft preparation, T.M., M.M., and O.Y.; writing-review and editing, T.M. B.M., and Y.H.; supervision, Y.H.; project administration, Y.H.; funding acquisition, T.M. 
All authors have read and agreed to the published version of the manuscript.

\section{Acknowledgments}

We would like to thank Editage (www.editage.com) for English language editing.

\section{References}

[1] Marchesini G, Brizi M, Bianchi G, Tomassetti S, Bugianesi E, Lenzi M, et al. Nonalcoholic fatty liver disease: a feature of the metabolic syndrome. Diabetes. 2001;50:1844-50.

[2] Marchesini G, Bugianesi E, Forlani G, Cerrelli F, Lenzi M, Manini R, et al. Nonalcoholic fatty liver, steatohepatitis, and the metabolic syndrome. Hepatology. 2003;37:917-23.

[3] Sanyal AJ; American Gastroenterological Association. AGA technical review on nonalcoholic fatty liver disease. Gastroenterology. 2002;123:1705-25.

[4] Mahfood Haddad T, Hamdeh S, Kanmanthareddy A, Alla VM. Nonalcoholic fatty liver disease and the risk of clinical cardiovascular events: a systematic review and meta-analysis. Diabetes Metab Syndr. 2017;11:S209-16.

[5] Malaguarnera M, Di Rosa M, Nicoletti F, Malaguarnera L. Molecular mechanisms involved in NAFLD progression. J Mol Med (Berl). 2009;87:679-95.

[6] Cai C, Song X, Chen Y, Chen X, Yu C. Relationship between relative skeletal muscle mass and nonalcoholic fatty liver disease: a systematic review and meta-analysis. Hepatol Int. 2020;14:115-26.

[7] Kim JA, Choi KM. Sarcopenia and fatty liver disease. Hepatol Int. 2019;13:674-87.

[8] Koo BK, Kim D, Joo SK, Kim JH, Chang MS, Kim BG, et al. Sarcopenia is an independent risk factor for non-alcoholic steatohepatitis and significant fibrosis. J Hepatol. 2017;66:123-31.

[9] Petta S, Ciminnisi S, Di Marco V, Cabibi D, Cammà C, Licata A, et al. Sarcopenia is associated with severe liver fibrosis in patients with non-alcoholic fatty liver disease. Aliment Pharmacol Ther. 2017;45:510-8.

[10] The Lancet Diabetes Endocrinology. Sarcopenia: a fate worth challenging. Lancet Diabetes Endocrinol. 2014;2:183.

[11] Kleiner DE, Brunt EM, Van Natta M, Behling C, Contos MJ, Cummings OW, et al. Design and validation of a histological scoring system for nonalcoholic fatty liver disease. Hepatology. 2005;41:1313-21.

[12] Brunt EM, Kleiner DE. Pathology of NAFLD. In: Farrell GC, McCullough AJ, Day CP, editors. Nonalcoholic fatty liver disease: a practical guide. Hoboken: Wiley-Blackwell; 2013. p. 27-36. 
[13] Eguchi Y, Mizuta T, Sumida Y, Ishibashi E, Kitajima Y, Isoda H, et al. The pathological role of visceral fat accumulation in steatosis, inflammation, and progression of nonalcoholic fatty liver disease. $\mathrm{J}$ Gastroenterol. 2011;46:70-8.

[14] Arner P. Human fat cell lipolysis: biochemistry, regulation and clinical role. Best Pract Res Clin Endocrinol Metab. 2005;19:471-82.

[15] Donnelly KL, Smith Cl, Schwarzenberg SJ, Jessurun J, Boldt MD, Parks EJ. Sources of fatty acids stored in liver and secreted via lipoproteins in patients with nonalcoholic fatty liver disease. $\mathrm{J}$ Clin Invest. 2005;115:1343-51.

[16] Holt HB, Wild SH, Wood PJ, Zhang J, Darekar AA, Dewbury K, et al. Non-esterified fatty acid concentrations are independently associated with hepatic steatosis in obese subjects. Diabetologia. 2006;49:141-8.

[17] Rolo AP, Teodoro JS, Palmeira CM. Role of oxidative stress in the pathogenesis of nonalcoholic steatohepatitis. Free Radic Biol Med. 2012;52:59-69.

[18] Takaki A, Kawai D, Yamamoto K. Multiple hits, including oxidative stress, as pathogenesis and treatment target in non-alcoholic steatohepatitis (NASH). Int J Mol Sci. 2013;14:20704-28.

[19] Nassir F, Ibdah JA. Role of mitochondria in nonalcoholic fatty liver disease. Int J Mol Sci. 2014;15:8713-8742.

[20] Polyzos SA, Kountouras J, Zavos C, Tsiaousi E. The role of adiponectin in the pathogenesis and treatment of non-alcoholic fatty liver disease. Diabetes Obes Metab. 2010;12:365-83.

[21] Tilg H, Hotamisligil GS. Nonalcoholic fatty liver disease: cytokine-adipokine interplay and regulation of insulin resistance. Gastroenterology. 2006;131:934-45.

[22] Polyzos SA, Kountouras J, Mantzoros CS. Leptin in nonalcoholic fatty liver disease: a narrative review. Metabolism. 2015;64:60-78.

[23] Lumeng CN, Bodzin JL, Saltiel AR. Obesity induces a phenotypic switch in adipose tissue macrophage polarization. J Clin Invest. 2007;117:175-84.

[24] Fujisaka S, Usui I, Bukhari A, Ikutani M, Oya T, Kanatani Y, et al. Regulatory mechanisms for adipose tissue M1 and M2 macrophages in diet-induced obese mice. Diabetes. 2009;58:2574-82.

[25] Munukka E, Pekkala S, Wiklund P, Rasool O, Borra R, Kong L, et al. Gut-adipose tissue axis in hepatic fat accumulation in humans. J Hepatol. 2014;61:132-8.

[26] Tordjman J, Divoux A, Prifti E, Poitou C, Pelloux V, Hugol D, et al. Structural and inflammatory heterogeneity in subcutaneous adipose tissue: relation with liver histopathology in morbid obesity. $\mathrm{J}$ 
Hepatol. 2012;56:1152-8.

[27] du Plessis J, van Pelt J, Korf H, Mathieu C, van der Schueren B, Lannoo M, et al. Association of adipose tissue inflammation with histologic severity of nonalcoholic fatty liver disease. Gastroenterology. 2015;149:635-48.

[28] Bhanji RA, Narayanan P, Moynagh MR, Takahashi N, Angirekula M, Kennedy CC, et al. Differing impact of sarcopenia and frailty in nonalcoholic steatohepatitis and alcoholic liver disease. Liver Transpl. 2019;25:14-24.

[29] Alferink LJM, Trajanoska K, Erler NS, Schoufour JD, de Knegt RJ, Ikram MA, et al. Nonalcoholic fatty liver disease in the Rotterdam study: about muscle mass, sarcopenia, fat mass, and fat distribution. $J$ Bone Miner Res. 2019;34:1254-63.

[30] Cruz-Jentoft AJ, Baeyens JP, Bauer JM, Boirie Y, Cederholm T, Landi F, et al. Sarcopenia: European consensus on definition and diagnosis: report of the European Working Group on Sarcopenia in Older People. Age Ageing. 2010;39:412-23.

\section{Supplementary Files}

This is a list of supplementary files associated with this preprint. Click to download.

- Additionalfile1.docx

- Additionalfile2.docx

- Additionalfile3.docx 